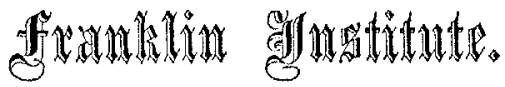

\section{Proceedings of the Stated Meeting, Sept. 20th, 1871.}

The meeting was called to order by the President, Mr. Coleman Sellers.

The minutes of the last meeting were read and approved.

The Actuary submitted the minutes of the Board of Managers and reported that, at their stated meeting held September 13th, donations to the library were received from

The Royal Astronomical and Geographical Societies of London. The Manchester Steam Users Association of Manchester, England. The Austrian Society of Engincers and Architects, Vienna. From the American Philosophical Society, Philadelphia. The Smithsonian Institution, at Washington. The U.S. Coast Survey, Washington, D. C. And from Prof. J. E. Nourse, U. S. N.

The Committee appointed to investigate the subject of the Horsepower of Steam Boilers reported progress.

The Secretary then read his Monthly Report on Novelties in Science and the Mechanic Arts, after which the meeting adjourned.

William H. WaHL, Secretary.

Proceedings of the Stated Meeting, Oct. 18th, 1871.

The meeting was called to order by the President, Mr. Coleman Sellers.

The minutes of the last meeting were read and approved.

The Actuary submitted the minutes of the Board of Managers and reported that, at their last meeting held October 11th, donations to the library were received from

The New York Canal Commissioners. Georgia Historical Society. And the Department of the Interior, Washington.

The Committee appointed to investigate the Horse-power of Steam Boilers reported progress and were continued.

Under the head of new business, the President announced that the Board of Managers had approved a resolution of the "Committee on Science and the Arts," awarding the Elliott Cresson Medal to $\mathbf{M r}$. B. C. Tilghman, for the discovery of a process of cutting and engra $v$ ing hard substances.

The Secretary then read his Monthly Report on Science and the Arts, after which the meeting adjourned.

WILLIAM H. WAḦL, Secretary. 